\title{
Astronomy Magazine Fellowship
}

\author{
Jordan Rice \\ Carthage College \\ Kenosha, Wisconsin
}

\section{Synopsis}

The Astronomy Magazine Fellowship was an opportunity to work with Astronomy Magazine for 10 weeks in the summer as a student sciencewriter.

\section{Goals and Project Value}

The Astronomy Magazine Fellowship goal for the student science writer was to work with the editor to identify astronomy-related issues and topics for stories in a variety of forms - hard news, features, blogs and an enterprise project. These articles would appear as news stories in Astronomy, and as blogs and breaking news on astronomy.com. The student would have his or her own desk and access to editors in order to check in on assignments; review sources and story angles; and, edit draft copies. The student would also have a role in creating content for Astronomy's 2017 Great American Eclipse website, which will educate the public about solar science and the best ways to view the coming eclipse. Finally, the student would work with the editor to craft a feature-length story for the magazine on an agreed upon topic.

The value would be for the student to leave with a portfolio of short clips and one longer piece to help launch him or her into a career in science communications, or assist in better explaining his or her own research to the public and funding agencies.

My personal objectives/goals for this fellowship were to develop my skill set, including learning journalism techniques, sharpening writing skills, honing communication skills, and learning new computer programs.I also wanted to make professional connections and learn more about astronomy related topics.

\section{Evaluation Results}

At the conclusion of this fellowship, the following goals were accomplished.

1. I worked with the editor and associate editors to help identify astronomy-related issues that went into my writing of over $30+$ blog articles. Writing these numerous articles helped sharpened my science writing skills.

2. I had my own office and desk in the building in Waukesha and worked closely with the associate editors to get assignments; review sources, and story angles; and, edit draft copies.

\footnotetext{
${ }^{1}$ Special thanks to the Wisconsin Space Grant Consortium (WSGC) who provided the necessary funding for student involvement on these projects Introduction \& Background
} 
3. I contributed to creating content for the Astronomy's 2017 Great American Eclipse website.

4. I made professional connections by interviewing and speaking to well-known scientists in the field of Astronomy, including Tabetha Boyajian (for whom Tabby's star is named) and Seth Shostak (senior astronomer at SETI). Speaking to these individuals increased my knowledge of astronomy topics and astronomy-related fields.

5. I worked closely with the editor and associate editors and learned new journalism techniques and communication skills. They were wonderful people that made my time at the magazine both enjoyable and beneficial.

6. I learned new technology/programs including Knight Lab Timeline and SiteCore.

7. I do have a portfolio of short clips and articles from my writing for the blog, such as "Black holes sing, but only in X-ray", "It may take 1500 years to meet E.T.", and "King Tut may have carried a Meteor-Forged Dagger". However, I did not get to create a longer piece during my internship.

\section{Evaluation Analysis}

Based on my experience and goals met, I highly recommend this fellowship to anyone who is interested in learning about important astronomical research and how to write in a more technical scientific way. This fellowship has afforded me many opportunities to speak to and/or interview important scientists in the field of astronomy. This fellowship also creates a portfolio that could help launch me into a career in science communications, or assist in better explaining my own research to the public and funding agencies. In addition, the experience of working at a wellknown magazine with people who are highly regarded in this field is a benefit of its own.

\section{General Information}

Astronomy Magazine is the world's most popular publication on the subject. The title was founded in Milwaukee, Wisconsin, in 1973, and is currently owned by Kalmbac Publishing Co., based in Waukesha. Kalmbach owns more than a dozen popular magazine titles, including Astronomy's sister publication, Discover. Astronomy's editors have decades of combined experience in the science and hobby, which gives the staff access to a large pool of sources that include the biggest names in the field. Our popular website, astronomy.com, brings in millions of visitors each year, and our Facebook page boasts more than 1 million likes. 